Paper:

\title{
Weather Conditions and Warm Air Masses in Southern Sakha During Active Forest Fire Periods
}

\author{
Hiroshi Hayasaka* ${ }^{* \dagger}$, Koji Yamazaki**, and Daisuke Naito*** \\ * Arctic Research Center, Hokkaido University \\ N21 W11, Kita-ku, Sapporo, Hokkaido 001-0021, Japan \\ †Corresponding author, E-mail: hhaya@eng.hokudai.ac.jp \\ **Faculty of Environmental Earth Science, Hokkaido University, Sapporo, Japan \\ ${ }^{* * *}$ Center for International Forestry Research (CIFOR), Bogor, Indonesia \\ [Received May 30, 2018; accepted February 5, 2019]
}

\begin{abstract}
Forest fires are a common and destructive natural disaster in Russia. Weather conditions during active forest fire periods in southern Sakha (Eastern Siberia) at high latitudes $\left(58-65^{\circ} \mathrm{N}, 120-140^{\circ} \mathrm{E}\right)$ were evaluated. Periods of high fire activity during 2002 to 2016 were identified using MODIS (moderate resolution imaging spectroradiometer) hotspot data by considering the number of daily hotspots and their continuity. Weather conditions during the top seven periods of high fire activity were analyzed using atmospheric reanalysis data for upper $(500 \mathrm{hPa})$ and lower levels $(925 \mathrm{hPa})$. Our results showed that active fires occurred under varied weather conditions and it was difficult to find common weather patterns at both upperand lower-levels during the seven most active fire periods. Furthermore, it was apparent that the northward movement of warm air masses (cTe: continental temperate) from lower latitudes $\left(\sim 40^{\circ} \mathrm{N}\right)$ toward southern Sakha tended to exacerbate fires mainly due to strong wind conditions during the seven most active fire periods. In particular, on peak hotspot days, warm air masses from the south existed commonly near southern Sakha. This northward movement of warm air masses can be used to forecast fire and predict future fires in the region.
\end{abstract}

Keywords: warm air mass, advection, meandering westerlies, hotspot, forest fire

\section{Introduction}

A number of serious natural disasters, including floods and major forest fires, have plagued Russia in recent years [1]. Forest fires are a natural and inherent element in the functioning of boreal forests [2]; however, air temperatures in high latitudes have increased by $0.06^{\circ} \mathrm{C}$ year ${ }^{-1}$ over the last 30 years, approximately twice as much as the increase in global temperatures [3]. Climate-induced fire frequency and burnt areas are increasing within Siberian forests, and forest fire frequency has been correlated with air temperature anomalies, drought indices (The Stan- dardized Precipitation Evapotranspiration Index) [4], the standardized precipitation index (SPI) [5], and the Canadian Forest Fire Weather Index (FWI) [6].

Fuel for forest fires in the boreal forests of eastern Siberia comprises deciduous needle-leaf, predominantly from Larix on permafrost. These trees have a shallow root system extending in the upper organic and active layer and are adapted to permafrost soils. Because of the annual litter fall and low decomposition rates, these forests provide organic layers and thus, high fuel levels [7]. Increased fire activity has been observed since approximately 1990 [8] for the periods of 1950-2015 in Alaska [9] and 19552009 in Sakha [10], which have been linked to increasing temperatures [11].

Fire size is sensitive to weather in the days to weeks following ignition, particularly the post-ignition timing of precipitation [12]. For example, prolonged periods of warm and dry conditions coincident with atmospheric blocking that persisted for a few weeks after ignition enabled the growth of large forest fires. Extensive fires in 2004 may have been related to a persistent blocking ridge over Alaska [13,14]. The burnt area in the North American boreal forest was controlled by the frequency of midtropospheric blocking highs that caused rapid fuel drying $[15,16]$. Furthermore, $500 \mathrm{hPa}$ height anomalies were well correlated with the seasonal burnt area over large regions of Canada and Alaska [17, 18].

In this study, we focused on weather conditions during active fire periods in the boreal forests of southern Sakha. The Republic of Sakha is the largest region ( 3.08 million $\mathrm{km}^{2}$ ) in the Republics of Russia and is located near the Arctic Circle. The boreal forest area in Sakha is approximately 1.43 million $\mathrm{km}^{2}$, and the average annual burnt area in protected forests is $1810 \mathrm{~km}^{2}$ (1955-2009) [19]. To provide a clearer explanation of increasing forest fires in Sakha, it is necessary to evaluate the impact of ongoing climate change on forest fires. As described above, their relationship is complex. Here, we focus on weather conditions during recent active fire periods in the boreal forests of southern Sakha. Similar research focusing on boreal forest fires in Alaska has been conducted which examined synoptic-scale weather conditions [9]. In the present study, we use MODIS hotspot 


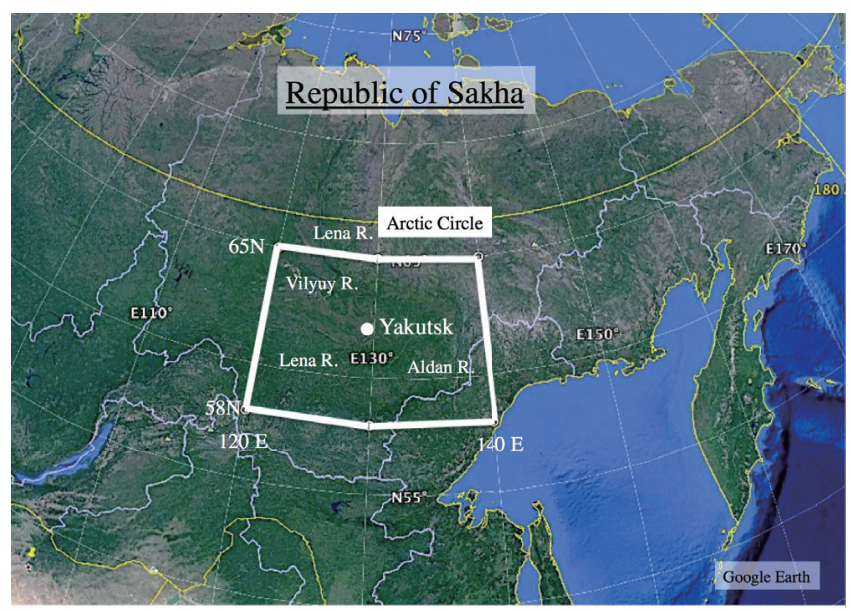

Fig. 1. Southern Sakha (study area, 58-65N, 120-140E).

data to represent the spatiotemporal distribution of fires. Because Russian forest fire data are mainly collected regarding so-called protected forests, spatiotemporal data are often lacking. To clarify weather conditions, we analyzed atmospheric reanalysis data sets (height, temperature, wind direction, and wind velocity and direction) at upper $(500 \mathrm{hPa})$ and near surface $(925 \mathrm{hPa})$ levels. Upper level weather maps were used to evaluate meandering westerlies and high-pressure systems. Lower level temperature maps were analyzed to examine warm air mass formation, northward advection, and fire relationships. Lower level wind maps were also used to explain fire activity on hotspot peak days.

\section{Forest Fires in Southern Sakha}

\subsection{Southern Sakha and Study Area}

Sakha, a republic of the Russian Federation in Eastern Siberia, lies between $56-73^{\circ} \mathrm{N}$ and $106-160^{\circ} \mathrm{E}$ (hereafter, a simpler expression without the degree sign will be used, e.g., 56-73N). Sakha's boreal forest or taiga lies mainly to the south of the Arctic Circle. The study area covers the southern part of Sakha's boreal forest area $(58-65 \mathrm{~N}, 120-140 \mathrm{E})$ and is defined by considering hotspot (HS for short hereafter) densities from previous research [19]. The study area, called "southern Sakha" is shown in Fig. 1. Yakutsk, the capital of Sakha, is located at $62 \mathrm{~N}$ and $129.8 \mathrm{E}$ and is located near the center of the study area.

Sakha's forests consist mainly of larch, pine, and spruce, with a ground cover of Vaccinium vitis-idaea, moss, and lichen. Crown fires are infrequent. Mountains in the south of Russia block the flow of warm air masses from the Indian Ocean while cold air masses from the Arctic Sea enter across the plains to the west and north.

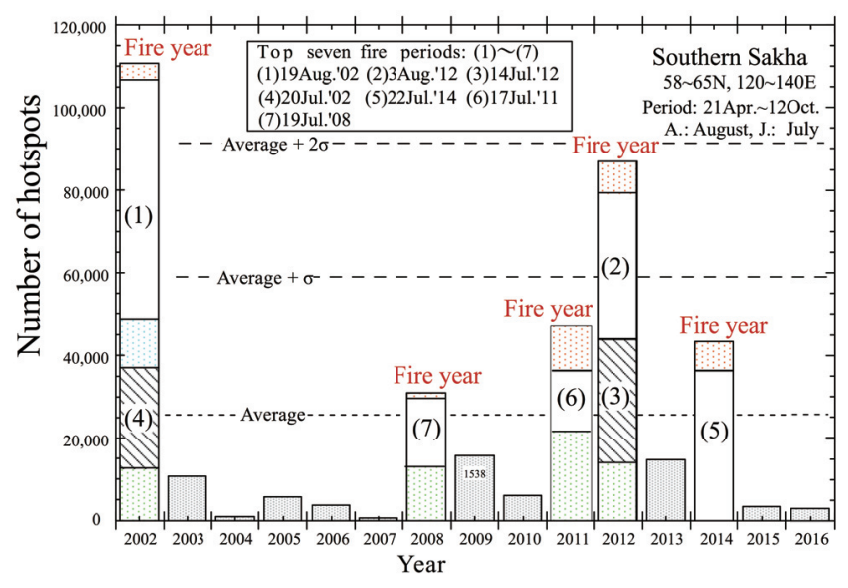

Fig. 2. Annual number of hotspots (HSs) for the period 2002-2016 and total number of HSs during the top seven fire periods. Each bar in the five fire years is divided into multiple periods to show fire occurrence tendency. Periods are named pre-fire, fire, and post-fire periods, and are stacked in chronological order. For example, the leftmost bar for 2002 (the top fire year) is divided into several fire periods; a pre-fire period (green dots), (4) for “(4) 20 Jul. '02," (1) for “(1) 19 Aug. '02," and then a post-fire period (red dots) (see Table 1).

\subsection{Recent Fire History and High-Fire Periods}

The history of forest fires in Sakha was analyzed using fire data (annual burnt area and number of fires from 1955-2009) provided by the Sakha Ministry of Forestry and personal communications with Russian scientists. Furthermore, Hayasaka [19] reported on the history of forest fires and recent fire tendencies using HS data from 2002-2010. Hayasaka [10] also showed lightning occurrence during 2002 fire season in Sakha. Here, we analyzed 15 years of HS data (2002-2016) detected by moderate resolution imaging spectroradiometer (MODIS) on the Terra and Aqua satellites to evaluate forest fires in Sakha. MODIS HS data collected during 2002-2016 were obtained from the NASA Fire Information for Resource Management System (FIRMS; MODIS Collection 6, https://firms.modaps.eosdis.nasa.gov/download/, latest access: December 15, 2017).

HS data tends to include thermal anomalies of small areas such as ironworks and buildings reflecting sunlight. Whereas, short time and small fires tend to be excluded in HS data [20,21]. In this paper, as high-fire periods are extracted using a large number of HSs, the above-mentioned fire detection error could be ignored.

Figure 2 shows that the average number of HSs per year was 25,589, and there were five active fire years (2002, 2008, 2011, 2012, and 2014) where HS numbers exceeded the average value. The total number of HSs during these years was 554,498 , or $77.1 \%$ of total HSs. The largest (smallest) annual number of HSs was 110,765 (570) in 2002 (2007). Thus, the largest number of annual HSs was 194 times greater than the smallest (Fig. 2). We call those years "fire years" when HS numbers exceeded 
Table 1. Top seven most active fire periods.

\begin{tabular}{|l|c|c|l|}
\hline $\begin{array}{c}\text { Fire period } \\
\text { (rank, date of HS peak) }\end{array}$ & $\begin{array}{c}\text { No. of HS } \\
\text { peak day }\end{array}$ & $\begin{array}{c}\text { Total No. of HS } \\
\text { of each fire-period }\end{array}$ & $\begin{array}{c}\text { No. of fire days } \\
\text { (fire-period) }\end{array}$ \\
\hline (1) 19 Aug. '02 & 8,796 & 57,033 & 15 (Aug. 12-25) \\
(2) 3 Aug. '12 & 8,118 & 35,254 & 12 (Jul. 25-Aug. 5) \\
(3) 14 Jul. '12 & 5,829 & 29,756 & 10 (Jul. 7-16) \\
(4) 20 Jul. '02 & 5,270 & 23,752 & 12 (Jul. 14-25) \\
(5) 22 Jul. '14 & 4,755 & 36,002 & 22 (Jul. 14-Aug. 4) \\
(6) 17 Jul. '11 & 3,205 & 14,871 & 11 (Jul. 12-22) \\
(7) 19 Jul. '08 & 2,698 & 12,359 & 6 (Jul. 16-21) \\
\hline
\end{tabular}

HS: Hotspot

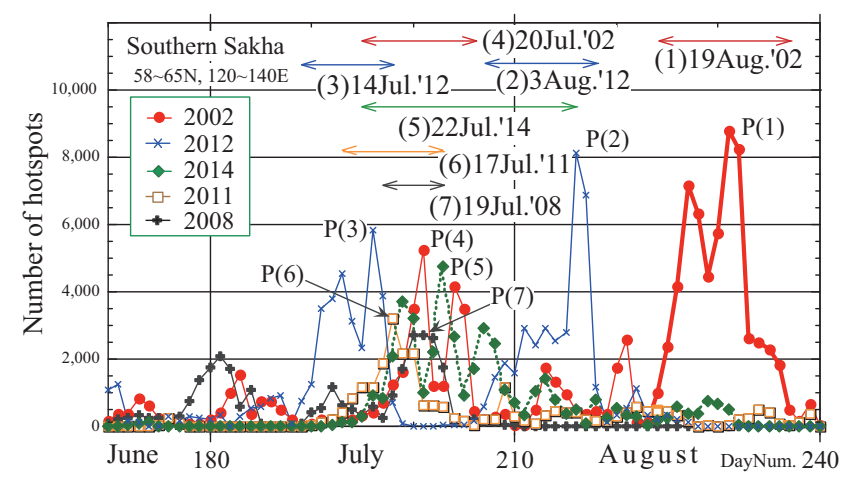

Fig. 3. The number of daily hotspots (HSs) during fire years. The average number of daily HSs for the top seven fire periods, and average fire periods. Horizontal lines with arrows at each end indicate each fire period. (1)-(9) show HS peak of each fire periods.

the average value.

Weather conditions during fire years were the focus of this study. To clarify conditions, we analyzed active fire periods using daily HS data. Periods of high fire activity were defined following previous research [9]; that is, consecutive fire days when the number of daily HS exceeded 300.

In total, seven periods of high-fire activity (daily HS peaks exceeding 2650) were selected to discuss common weather conditions and warm air advection. Active fire periods were ranked according to the highest number of HSs during each fire period and named using their ranking, date, month, and year (e.g., "(1) 19 Aug. '02," "(2) 3 Aug. '12," and so on). The top seven fire periods are summarized in Table 1 and depicted in Figs. 2 and 3. Fig. 3 shows the daily number of HSs for the top five fire years and the duration of the top seven fire periods.

\section{Weather Conditions During Active Fire Pe- riods}

Upper and lower level synoptic- and meso-scale circulation patterns, and lower level temperature distributions during fire periods were analyzed. Daily and six hourly data from the NCEP/NCAR reanalysis data sets [22] were

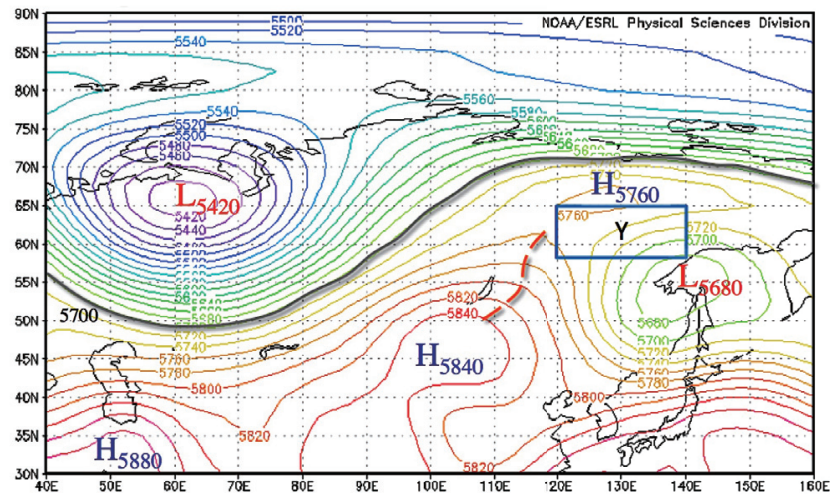

Fig. 4. Average weather map (August 12-19, height [m] at $500 \mathrm{hPa}$ ) of the top fire period “(1) 19 Aug. '02." The study area $(58-65 \mathrm{~N}, 120-140 \mathrm{E})$ is shown with a rectangle and " $\mathrm{Y}$ " shows the location of Yakutsk. Each major high- and lowpressure system is marked with " $\mathrm{H}$ " and "L," respectively, and their average height is indicated by the closest isoline. The major ridge is indicated by a dashed line. The $5700 \mathrm{~m}$ isoline is thickened to highlight the estimated location of the westerly wind.

utilized and plotted using the Earth System Research Laboratory, National Oceanic \& Atmospheric Administration website (NOAA ESRL, https://www.esrl.noaa.gov/ psd/data/gridded/data.ncep.reanalysis.html, latest access: January 21, 2018).

\subsection{Upper Level High-Pressure Systems During Active Fire Periods}

Stagnating high-pressure systems are synonymous with the warm and dry conditions or fire favorable conditions [23]. To clarify the formation mechanisms of highpressure systems at upper-levels over southern Sakha, weather maps averaged from the first HS day to the peak HS day were analyzed. This is because the identification of stagnating high- and low-pressure systems is more important here than the daily movements of cutoff highs and lows. This kind of upper-level weather map also helps to identify large meandering westerlies over Russia due to stagnating low-pressure systems.

The average weather map $(500 \mathrm{hPa})$ for the top fire period ((1) 19 Aug. '02, see Table 1), is shown in Fig. 4. 
The following features are apparent: (1) large meandering westerlies over Russia due to a stagnating low-pressure system ( $\left.\mathrm{L}_{5420}, 66 \mathrm{~N} 60 \mathrm{E}\right),(2)$ a stagnating high-pressure system $\left(\mathrm{H}_{5760}, 66 \mathrm{~N} 125 \mathrm{E}\right)$ located in the north of the study area, and (3) a stagnating low-pressure system $\left(\mathrm{L}_{5680}\right.$, $55 \mathrm{~N}$ 140E) located over the northern Okhotsk Sea. The low-pressure system over the northern Okhotsk Sea, stagnated at approximately $50-60 \mathrm{~N}$, forms a Rex block with $\mathrm{H}_{5760}$; the ensuing ridge on the east side of Lake Baikal almost reaches $65 \mathrm{~N}$. Hence, we conclude that stagnating high-pressure systems (fire favorable conditions) over southern Sakha are formed by the large westerlies meandering over Russia due to two stagnating low-pressure systems located in the far west $(66 \mathrm{~N} 60 \mathrm{E})$ and southeast $(55 \mathrm{~N} 140 \mathrm{E})$ of southern Sakha.

Upper level weather maps for the remaining major fire periods (Table 1) also showed various types of highpressure systems over southern Sakha in all but one case. Only the fifth most active fire period "(5) 22 Jul. '14" showed evidence of a stagnating low-pressure system $\left(\mathrm{L}_{5640}, 58 \mathrm{~N} 137 \mathrm{E}\right)$ in the north of Okhotsk Sea (not shown). High-pressure systems for other fire periods were formed by a combination of meandering westerlies, cutoff highs and lows, ridges, and troughs. Thus, it was difficult to pinpoint a common weather pattern for active fires during the top seven active fire periods.

\subsection{Lower Level Warm Air Advection and Wind Conditions During Active Fire Periods}

In addition to warm and dry conditions under stagnating high-pressure systems at upper level, northward warm air advection and wind conditions during active fire periods are shown here.

Lower level temperature maps are used to investigate the northward advection of warm air masses (continental temperate, cTe). Large meandering westerlies over west Siberia (see Fig. 4) force northward advection of warm and dry air [23] from the arid continental interior $(\sim 30 \mathrm{~N}$ $60 \mathrm{E}$ ) as shown in the temperature map on August 12, 2002 (seven days before the peak HS day during the top fire period ((1) 19 Aug. '02)) in Fig. 5. A few warm air masses ((cTe; $305 \mathrm{~K}, 44 \mathrm{~N} \mathrm{83E),} \mathrm{(cTe;} 301 \mathrm{~K}, 47 \mathrm{~N} \mathrm{105E)} \mathrm{and}$ (cTe; $300 \mathrm{~K}, 58 \mathrm{~N} 101 \mathrm{E})$ ) from the south $(\sim 40 \mathrm{~N})$ had already advanced northeastward.

After this, the northernmost warm air mass (58N 101E) continued to move further northeastward, reached southern Sakha, and formed a $292 \mathrm{~K}$ cTe warm air mass on 15 August 2002 (see the inset in Fig. 5). The first large HS peak (7160, see Fig. 3) occurred under this warm air mass, located to the west of Yakutsk. On August 19 (peak HS day of (1) 19 Aug. '02), the warm air mass (cTe; $290 \mathrm{~K}, 64 \mathrm{~N}$ 122E) approaching from the east of Lake Baikal reached the west of Yakutsk as shown in Fig. 6. This movement of warm air resulted in the peak HS day of the most active fire period ((1) 19 Aug. '02, HSs; 8796, see Fig. 3 and Table 1). Active fire situation is clearly observed from the satellite image (note white smoke flows from the many tiny red HSs) in Fig. 7.

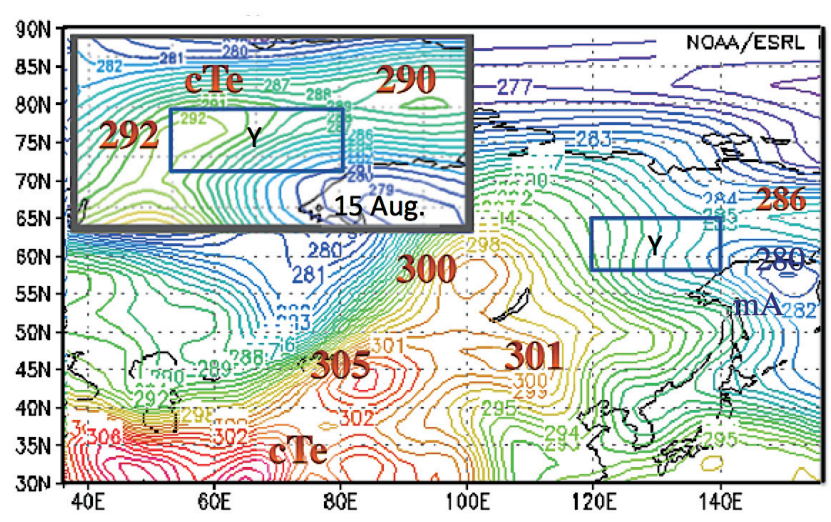

Fig. 5. Temperature maps of the first day (August 12) and four days before the peak HS day (August 15, $7160 \mathrm{HSs}$ ) during the top fire period “(1) 19 Aug. '02." The temperature map on August 15 is shown in the upper left of the figure. Major continental temperate (cTe; red) and maritime arctic $(\mathrm{mA}$; blue) values are indicated near the closest isoline.

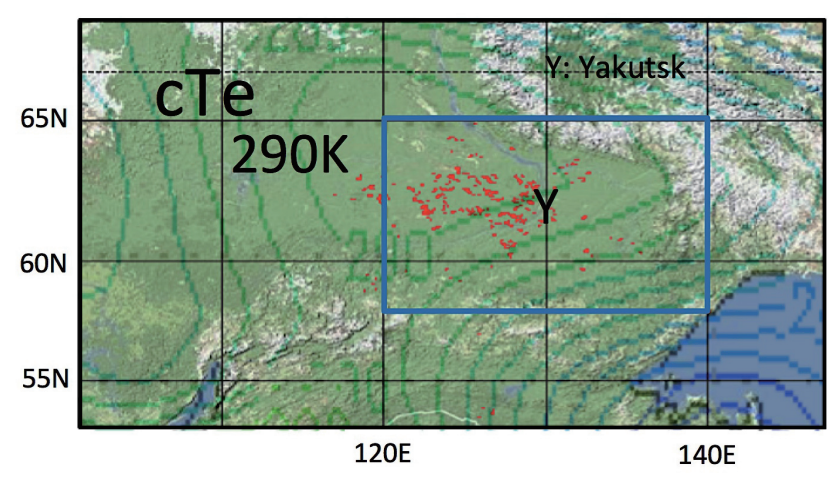

Fig. 6. Temperature map for the peak HS day (August 19, 2002, 8796 HSs) during the top fire period ((1) 19 Aug. '02) is superimposed on a Google map (www.google.com/maps, latest access: December 31, 2017). Hotspots in red are plotted on the Google map using computer-aided design software (Vector-Works ver. 2010 SP4).

To clarify lower level wind conditions in southern Sakha, weather maps on peak HS days are shown in Fig. 8. It is apparent that the region to the west of Yakutsk where the southeasterly (SE) wind velocity is relatively high (see wind velocity vectors in the western part or active fire region of the study area in Fig. 8) coincides approximately with the area where forest fires were active according to the satellite imagery in Fig. 7.

To evaluate wind conditions in the region to the west of Yakutsk, relative wind velocity $(\mathrm{Vr})$ was examined here [8]. $\mathrm{Vr}$ is derived from a geopotential height difference $(\Delta \mathrm{H})$ and we simply assume $\operatorname{Vr} \propto \Delta \mathrm{H}$. Two representative points, $\mathrm{P} 1$ and $\mathrm{P} 2$, are set to evaluate average $\mathrm{Vr}$ for the active fire region (see Figs. 6 and 7) in the west of Yakutsk as shown in Fig. 8. $\Delta \mathrm{H}$ is calculated by the equation, $\Delta \mathrm{H}=\mathrm{H}_{P 1}-\mathrm{H}_{P 2}$. Here, $\mathrm{H}_{P 1}$ and $\mathrm{H}_{P 2}$ are geopotential heights at $\mathrm{P} 1(60 \mathrm{~N} 130 \mathrm{E})$ and $\mathrm{P} 2(60 \mathrm{~N} 120 \mathrm{E})$, respectively. From Fig. 8, $\Delta \mathrm{H}=\mathrm{H}_{P 1}-\mathrm{H}_{P 2}=838-775=63 \mathrm{~m}$. 


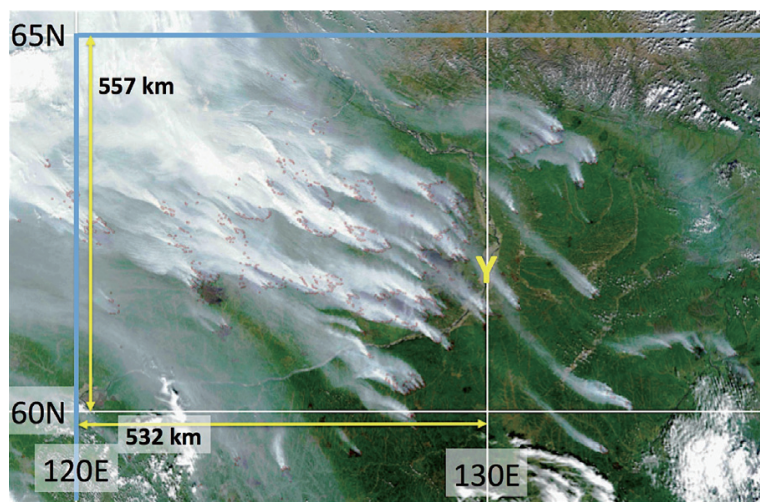

Fig. 7. Satellite image on the peak HS day (August 19, 2002, 8796 HSs) during the top fire period ((1) 19 Aug. '02). Image shows the most active concurrent widespread forest fires in southern Sakha under southeasterly wind. Each line of latitude, longitude, and the study area (blue line) are drawn in approximate positions and are not accurate. Image file name Russia.A2002231.0300.250m from MODIS Rapid Response System, NASA (most old MODIS images, including this image, are not available due to data disk failure at present).

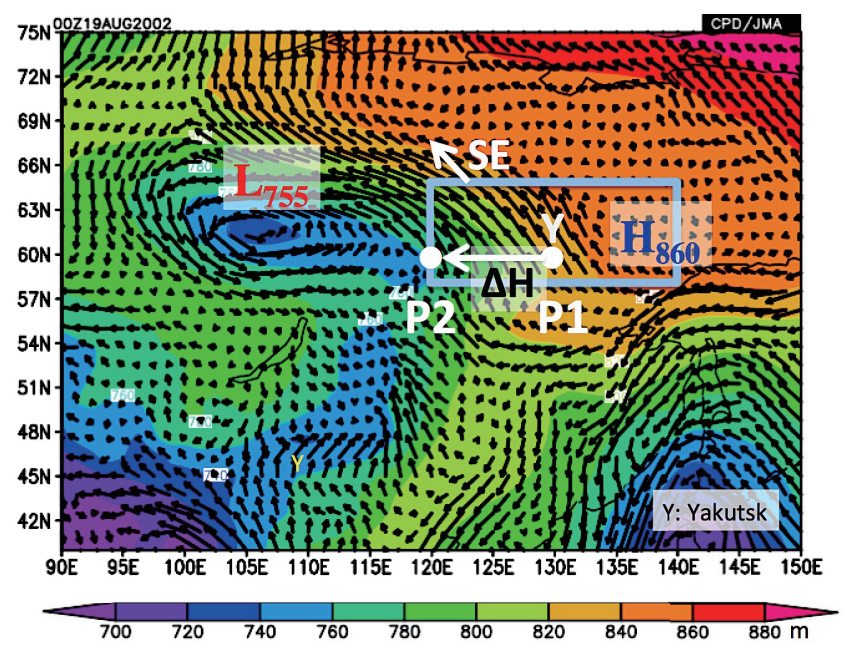

Fig. 8. Weather map with the wind direction and velocity vectors [24] $(925 \mathrm{hPa})$ on the peak HS day (August 19 , 2002). The height scale (m) is at the bottom. See caption for Fig. 4. $\mathrm{Vr}=63$ (SE), HSs $=8796$.

Other $\Delta \mathrm{H}$ during the active fire period is obtained from the daily weather maps. Daily changes of $\mathrm{Vr}$ during the top fire period ((1) 19 Aug. '02) are shown in Fig. 9. From Fig. 9, we infer that there is a relatively strong correlation between $\mathrm{Vr}$ and fires (HSs). The correlation equation is as follows:

$$
\begin{array}{rl}
\text { HSs }=876.21+48.534 \mathrm{Vr}+1 & 1.0673 \mathrm{Vr}^{2} \\
\left(\mathrm{R}^{2}=0.82109\right)
\end{array}
$$

where $\mathrm{Vr}$ is absolute value.

Errors in HSs varied from -33 to $33 \%$ except on the last two days (August 24 and 25). This suggests active

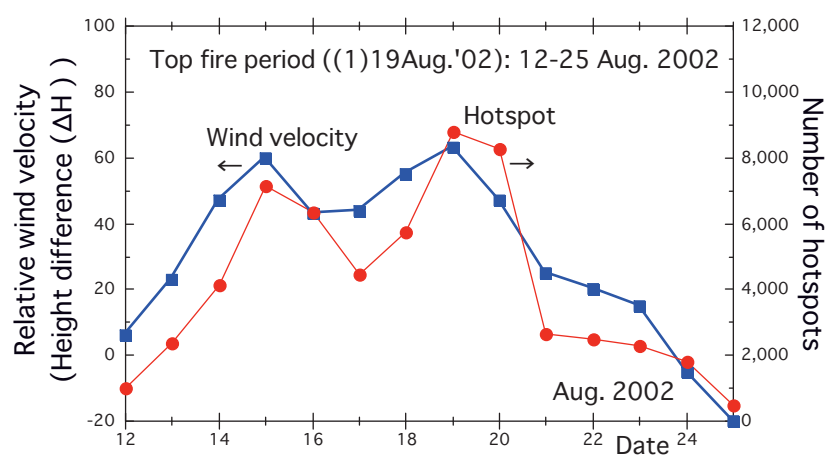

Fig. 9. Relative wind velocity $(\operatorname{Vr}(\Delta \mathrm{H}$, geopotential height difference)) and number of hotspots during the top fire period ((1) 19 Aug. '02).

fires that occurred are mostly related to Vr.

\subsection{Warm Air Masses on Other Peak Hotspot Days}

To clarify the relationship between active fires and northward advection of warm air masses, temperature maps $(925 \mathrm{hPa})$ for each peak HS day from the second to the seventh most active fire periods in Table $\mathbf{1}$ are superimposed on Worldview satellite images, as shown in Fig. 10 (except for the fourth most active fire period in 2002 ((4) 20 Jul. '02) in Fig. 10(c)). To evaluate relative wind velocity (Vr), two representative points, $\mathrm{P} 1$ and P2, are also set to each figure in Fig. $\mathbf{1 0}$ by considering each active fire region and major wind direction.

Warm air masses from the south are over the study area in each case. The temperatures (locations) for the second to the seventh most active fire periods are $297 \mathrm{~K} \mathrm{cTe}$ (60N 140E), $296 \mathrm{~K}$ cTe (Ridge $\sim 65 \mathrm{~N} 140 \mathrm{E}$ ), $294 \mathrm{~K}$ cTe (61N 123E), $294 \mathrm{~K}$ cTe (Ridge, $\sim 65 \mathrm{~N} 125 \mathrm{E}), 303 \mathrm{~K} \mathrm{cTe}$ (61N 133E), and $297 \mathrm{~K} \mathrm{cTe}(64 \mathrm{~N} \mathrm{133E)}$. These seven overlapped images (Figs. 6 and 10) suggest that the highest fire activity within each fire period occurs when a warm air mass from the south is advected to southern Sakha and under relatively strong wind conditions (see Figs. 6-10). Details of the daily movements of each warm air mass for the second to the seventh most active fire periods are not shown here; however, their movements are similar to those shown in Figs. 5 and 6.

Relatively strong wind conditions of the remaining fire periods (from the second to the seventh most active fire periods in Table 1) occurred under various weather patterns formed by a combination of low- and high-pressure systems, ridges, and troughs (not shown here). Thus, it was difficult to demonstrate a common lower-level weather pattern on peak HS days in active fire periods. However, each fire (HSs) on the peak HS day could be estimated using Eq. (1) except (5) 22 Jul. '14 (Fig. 10(d)). Errors in HSs varied from -19 to $37 \%$. Exceptional fires (HSs) during (5) 22 Jul. '14 occurred under strong wind velocity $(\mathrm{Vr}=-75)$ and wind direction $(\mathrm{NNW})$ due to a low-pressure system near the northern Okhotsk Sea $\left(\mathrm{L}_{540}, 56 \mathrm{~N} 139 \mathrm{E}\right)$. 


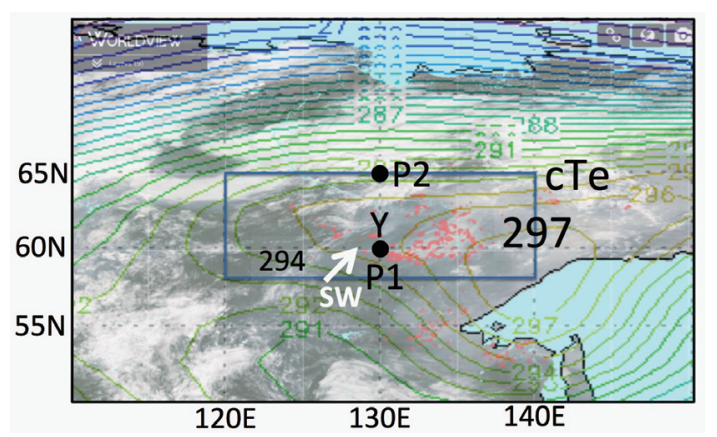

(a) On August 3, 2012 ((2) 3 Aug. ' 12). $\mathrm{Vr}=60$ (SW), HSs $=8118$.

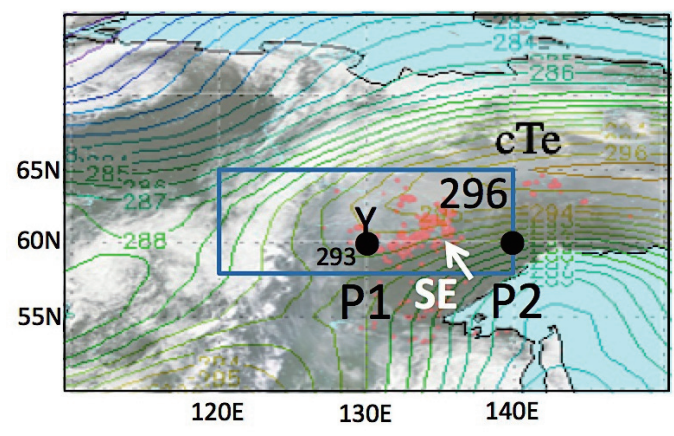

(b) On July 14, 2012 ((3) 14 Jul. ' 12). $\mathrm{Vr}=-50$ (SE), HSs $=5829$.

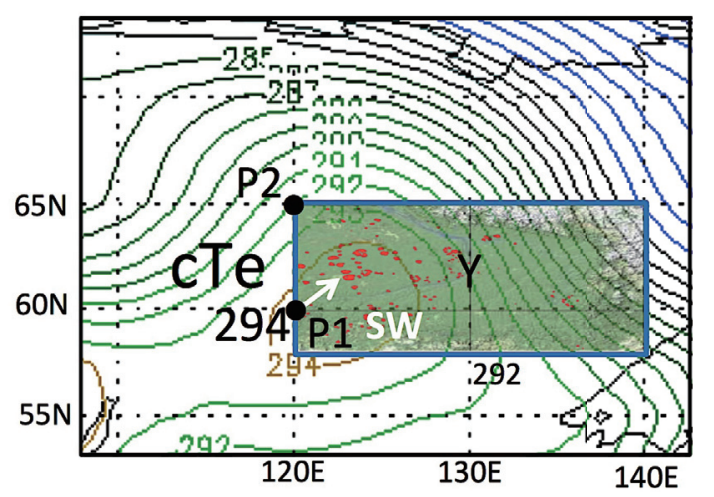

(c) On July 20, 2002 ((4) 20 Jul. ' 02$)$. Vr $=38$ (SW), HSs $=5270$.

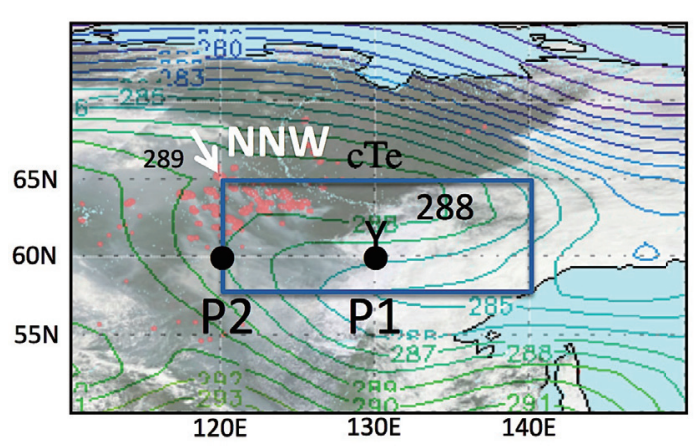

(d) On July 22, 2014 ((5) 22 Jul. '14). Vr $=-75$ (NNW), HSs $=4755$.

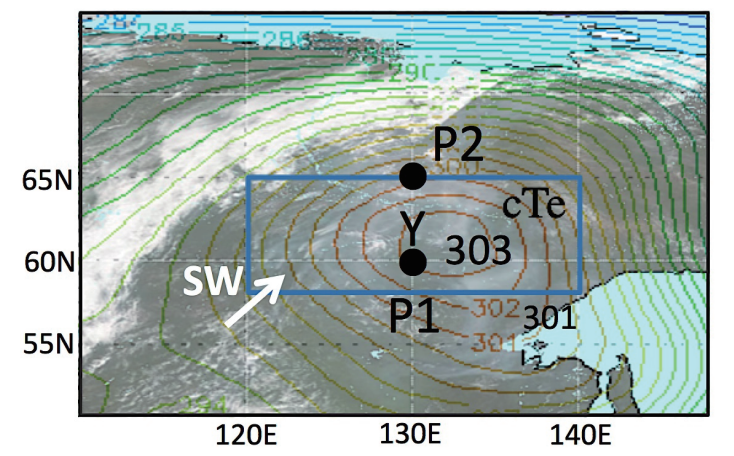

(e) On July 17, 2014 ((6) 17 Jul. ’11). Vr $=39$ (SW), HSs $=3205$.

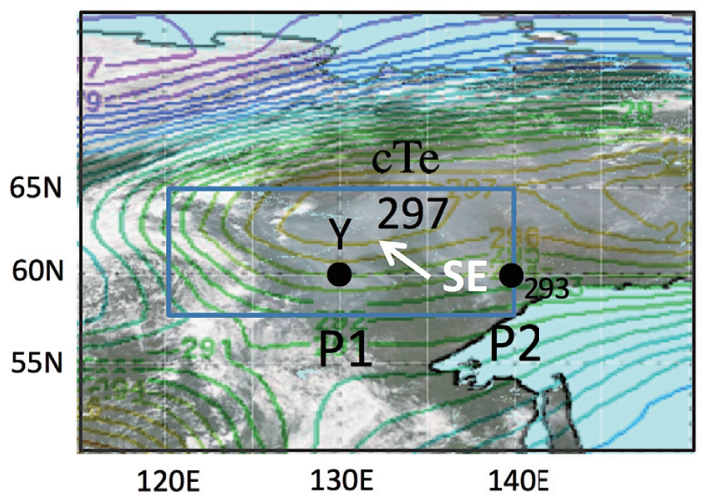

(f) On July 19, 2008 ((7) 19 Jul. '08). Vr $=-25$ (SE), HSs $=2698$.

Fig. 10. Temperature maps ( $925 \mathrm{hPa}$ ) superimposed on Worldview satellite images (except Fig. 10(c)) for each peak HS day during each fire period from the second most active fire period to the seventh most active fire period. Hotspots (red) appear automatically on the Worldview fire layer (EOSDIS Worldview, https://worldview.earthdata.nasa.gov/, latest access: December 31, 2017).

Finally, we could say most active fires in southern Sakha occurred under the presence of a warm air mass from the south and relatively strong wind conditions (Figs. 6-10).

\section{Conclusions}

In southern Sakha, active fires occurred mainly under stagnating upper-level (500 hPa) high-pressure systems. However, it was difficult to demonstrate common weather patterns at both upper- and lower-levels for active fires during the seven most active fire periods. We found that the northward movement of warm air masses from lower latitudes $(\sim 40 \mathrm{~N})$ toward southern Sakha tended to exacerbate fires mainly due to strong wind conditions during the fire periods. In particular, warm air masses existed near southern Sakha on all peak hotspot days. This northward movement of warm air masses from the south has the potential to be used for fire forecasting and prediction in the future.

\section{Acknowledgements}

This research was partially supported by the Center for International Forestry Research (CIFOR) with funding by the Government of Japan. This study was carried out under the Joint Re- 
search Program of the Japan Arctic Research Network Center. We would like to thank to "The NCEP/NCAR 40-Year Reanalysis Project."

\section{References:}

[1] R. Roffey, "Climate change and natural disasters," FOI-R-3874 SE, Report of Swedish Defence Research Agency (FOI), 2014.

[2] E. N. Valendik, "Temporal and Spatial Distribution of Forest Fires in Siberia," J. G. Goldammer and V. V. Furyaev (Eds.), "Fire in Ecosystems of Boreal Eurasia," pp. 129-138, Kluwer Academic Publishers, 1996.

[3] "IPCC, 2013. Climate Change 2013. The Physical Science Basis" T. F. Stocker, D. Qin, G.-K. Plattner, M. Tignor, S. K. Allen, J. Boschung, A. Nauels, Y. Xia, V. Bex, and P. M. Midgley (Eds.), Contribution of Working Group I to the 5th Assessment Report of the Intergovernmental Panel on Climate Change, Cambridge University Press, 2013, http://www.ipcc.ch/report/ar5/wg1/ [accessed January 21, 2018]

[4] E. I. Ponomarev, V. I. Kharuk, and K. J. Ranson, "Wildfires Dynamics in Siberian Larch Forests," Forests, Vol.7, No.125, doi:10.3390/f7060125, 2016.

[5] A. Hasegawa, M. Gusyev, and Y. Iwamiet, "Meteorological Drought and flood assessment Using the Comparative SPI Approach in Asia under Climate Change," J. Disaster Res., Vol.11, No.6, pp. 1082-1090, 2016.

[6] R. D. Field, A. C. Spessa, N. A. Aziz, A. Camia, A. Cantin, R. Carr, W. J. de Groot, A. J. Dowdy, M. D. Flannigan, K. Manomaiphiboon, F. Pappenberger, V. Tanpipat, and X. Wang, "Development of a Global Fire Weather Database," Nat. Hazards Earth Syst. Sci., Vol.15, pp. 1407-1423, 2015.

[7] M. Forkel, K. Thonicke, C. Beer, W. Cramer, S. Bartalev, and C. Schmullius, "Extreme fire events are related to previous-year surface moisture conditions in permafrost underlain larch forests of Siberia," Environ. Res. Lett., Vol.7, No.4, p. 044021, 2012.

[8] H. Hayasaka, "Recent Large Scale Fires in Boreal and Tropical Forests," J. Disaster Res., Vol.2, No.4, pp. 265-275, 2007.

[9] H. Hayasaka, H. Tanaka, and P. Bieniek, "Synoptic-scale fire weather conditions in Alaska," Polar Science, Vol.10, No.3, pp. 217-226, 2016.

[10] H. Hayasaka, "Recent Vegetation Fire Incidence in Russia," Global Environmental Research, AIRIES, Vol.15, No.1, pp. 5-13, 2011.

[11] N. P. Gillett, A. J. Weaver, F. W. Zwiers, and M. D. Flannigan, "Detecting the effect of climate change on Canadian forest fires," Geophys. Res. Lett., Vol.31, Issue 18, doi:10.1029/2004GL020876, 2004.

[12] J. T. Abatzoglou and A. K. Crystal, "Relative importance of weather and climate on wildfire growth in interior Alaska," Int. J. of Wildland Fire, Vol.20, pp. 479-486, 2011.

[13] G. Bell, "Special Climate Summary, April-July 2004, Hot in Alaska, Cool over Central North America, Wet in South-Central U.S.," http://www.cpc.ncep.noaa.gov/products/expert_assessment/ alaska.pdf [accessed October 27, 2015]

[14] G. Wendler, J. Conner, B. Moore, M. Shulski, and M. Stuefer, "Climatology of Alaskan wildfires with special emphasis on the extreme year of 2004," Theoretical and Applied Climatology, Vol.104, No.34, pp. 459-472, 2011.

[15] M. Fauria and E. A. Johnson, "Large-scale climatic patterns control large lightning fire occurrence in Canada and Alaska forest regions," J. Geophys. Res., Vol.111, G04008, doi:10.1029/2006JG000181, 2006.

[16] M. M. Fauria and E. A. Johnson, "Climate and wildfires in the North American boreal forest," Phil., Trans. R. Soc., B, Vol.363, Issue 1501, pp. 2317-2329, doi:10.1098/rstb.2007.2202, 2008.

[17] W. R. Skinner, B. J. Stocks, D. L. Martell, B. Bonsal, and A. Shabbar, "The association between circulation anomalies in the midtroposphere and area burned by wildland fire in Canada," Theor. Appl. Climatol., Vol.63, pp. 89-105, doi:10.1007/s007040050095, 1999.

[18] W. R. Skinner, M. D. Flannigan, B. J. Stocks, D. L. Martell, B. M. Wotton, J. B. Todd, J. A. Mason, K. A. Logan, and E. M. Bosch, "A $500 \mathrm{hPa}$ synoptic wildland climatology for large Canadian forest fires 1959-1996," Theor. Appl. Climatol., Vol.71, pp. 157-169, 2002

[19] H. Hayasaka, M. Fukuda, and K. Kushida, "Recent Large-scale Forest Fires in Boreal Forests and Climate Change -Discussion Based on Forest Fire and Weather Data in Alaska and Sakha-,' J. JAFSE, Vol.57, No.3, pp. 45-51, 2007 (in Japanese).

[20] E. Nunohiro, K. Katayama, K. Mackin, and J. G. Park, "Forest and Field Fire Search System Using MODIS Data," J. Adv. Comput. Intell. Intell. Inform., Vol.11, No.8, pp. 1043-1048, 2007.
[21] "MODIS Collection 6 Active Fire Product User's Guide," https://cdn.earthdata.nasa.gov/conduit/upload/3865/ MODIS_C6_Fire_User_Guide_A.pdf [accessed August 20, 2018]

[22] E. Kalnay, M. Kanamitsu, R. Kistler, W. Collins, D. Deaven, L. Gandin, M. Iredell, S. Saha, G. White, J. Woollen, Y. Zhu, M. Chelliah, W. Ebisuzaki, W. Higgins, J. Janowiak, K. C. Mo, C. Ropelewski, J. Wang, A. Leetmaa, R. Reynolds, R. Jenne, and D. Joseph, "The NCEP/NCAR 40-year reanalysis project," Bull. Amer. Meteor. Soc., Vol.77, pp. 437-470, 1996.

[23] University Corporation of Atmospheric Research, "The COMETRProgram," Blocking High (Associated Weather), last updated on June 24,2009 , http://www.meted.ucar.edu/norlat/ satfeatures/blocking_patterns/blocking_high.htm [accessed May 9, 2019]

[24] S. Kobayashi, Y. Ota, Y. Harada, A. Ebita, M. Moriya, H. Onoda, K. Onogi, H. Kamahori, C. Kobayashi, H. Endo, K. Miyaoka, and K. Takahashi, "The JRA-55 reanalysis: General specifications and basic characteristics," J. Meteorol. Soc. Japan, Vol.93, No.1, pp. 548, doi:10.2151/jmsj.2015-00, 2015.

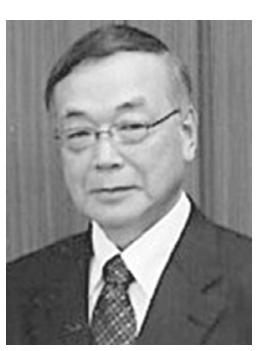

\section{Name:}

Hiroshi Hayasaka

\section{Affiliation:}

Arctic Research Center, Hokkaido University

Address:

N21 W11, Kita-ku, Sapporo, Hokkaido 001-0021, Japan

Brief Career:

1983- Guest Researcher, NBS (currently National Institute of Standards and Technology, NIST), United States Department of Commerce 1984-2015 Research Associate Professor, Graduate School of Engineering, Hokkaido University

2015-2017 Visiting Professor, Center for Southeast Asian Studies, Kyoto University

\section{Selected Publications:}

- H. Hayasaka, H. L. Tanaka, and P. A. Bieniek, "Synoptic-scale fire weather conditions in Alaska," Polar Science, Vol.10, Issue 3, pp. 217-226, 2016.

\section{Academic Societies \& Scientific Organizations:}

- Japan Association for Fire Science and Engineering (JAFSE)

- Combustion Society of Japan (CSJ)

- Meteorological Society of Japan (MSJ) 


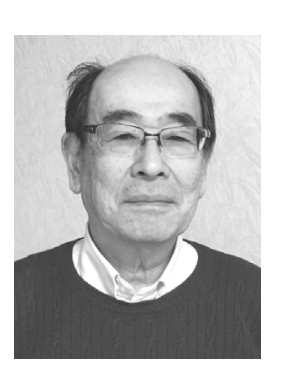

\section{Name:}

Koji Yamazaki

\section{Affiliation:}

Professor Emeritus, Project Researcher, Faculty of Environmental Earth Science, Hokkaido University

\section{Address:}

N10 W5, Kita-ku, Sapporo, Hokkaido 060-0810, Japan

Brief Career:

1973 Joined Division of Forecast, Japan Meteorological Agency (JMA)

1975-1994 Meteorological Research Institute, JMA

1994-2013 Professor, Hokkaido University

\section{Selected Publications:}

- K. Yamazaki et al., "Recent breakdown of the seasonal linkage between the winter North Atlantic Oscillation/Northern Annular Mode and summer Northern Annular Mode," J. of Climate, Vol.32, pp. 591-605, 2019.

- K. Yamazaki and Y. Shinya, "Analysis of the Arctic Oscillation simulated by AGCM,” J. Meteor. Soc. Japan, Vol.77, pp. 1287-1298, 1999.

Academic Societies \& Scientific Organizations:

- Meteorological Society of Japan (MSJ)

- American Meteorological Society (AMS)

- American Geophysical Union (AGU)

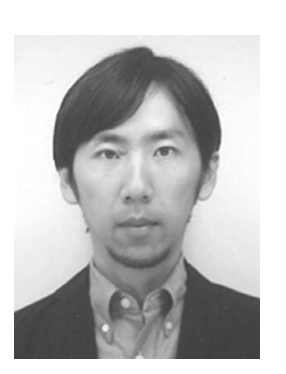

Name:

Daisuke Naito

Affiliation:

Center for International Forestry Research

\section{Address:}

Jalan CIFOR Situ Gede, Sindang Barang, Bogor (Barat) 16115, Indonesia

Brief Career:

2010 Research Fellow, Program in Agrarian Studies, Yale University

2011- Assistant Professor, The Research Institute for Humanity and Nature 2014- Scientist, Center for International Forestry Research

2018- Associate Professor, Faculty/Graduate School of Agriculture, Kyoto University

\section{Selected Publications:}

- D. Naito, "Forest Certification, Legality and Social Standards in Sarawak Malaysia," N. Ishikawa and R. Soda (Eds.), Human-Nature Interactions on the Plantation Frontier: An Ethnography of Anthropogenic Tropical Forests, Springer Nature (in press).

- S. Oomoto, T. Sato, and D. Naito (Eds.), "International Certification Schemes on Natural Resource," Tokyo University Press, 256pp., 2016.

- D. Naito, "Changing Forest Landscape and Local Communities in

Sabah, Malaysia," Tonanajia Kenkyu, Vol.52, Vol.1, pp. 3-21, 2014.

Academic Societies \& Scientific Organizations:

- International Union of Forest Research Organizations (IUFRO)

- Forests \& Livelihoods: Assessment, Research, and Engagement (FLARE) 